https://doi.org/ 10.32735/S0718-2201201900049753

239-259

\title{
DEÍXIS ESPACIAL EN EL RROMANÉ JORAJANÉ HABLADO EN CHILE: USO DE LOS DEMOSTRATIVOS EN ESPACIO DE ESCALA MENOR
}

Spatial deixis in rromané jorajané spoken in Chile: use of demonstratives in small-scale space

\author{
DIEGO LIZARRALDEC. \\ Universidad de Chile (Chile) \\ Universidad de La Frontera (Chile) \\ diego.lizarralde@ufrontera.cl \\ GASTÓN SALAMANCA G. \\ Universidad de Concepción (Chile) \\ gsalaman@udec.cl
}

Resumen

El artículo aborda uno de los modos de localización de entidades en situaciones espaciales estáticas: la deíxis espacial. Nuestro objetivo principal es describir la estructura y uso del sistema demostrativo en espacio de escala menor en la lengua hablada por los gitanos de Chile: el rromané jorajané. Para la obtención de los datos se utilizó The 1999 Demonstrative Questionnaire: 'THIS' and 'THAT' in comparative perspective (Wilkins, 1999). Los resultados del análisis destacan que los demostrativos espaciales del rromané jorajané constituyen un grupo altamente simétrico, que combina un componente semántico deíctico (la distinción próximo/distante), junto con contenidos gramaticales (género y número). Se trata de un sistema demostrativo binario en cuanto a la categoría de distancia respecto del centro deíctico. Se concluye también que la selección del demostrativo apropiado obedece al siguiente patrón: el demostrativo proximal tiene su área focal en la zona próxima al hablante, mientras que el demostrativo distal incluye en su campo de aplicación tanto la zona próxima al oyente como la zona distante al hablante.

Palabras clave: Localización estática; deíxis espacial; demostrativos; rromané hablado en Chile.

Abstract

This paper addresses one way of locating entities in static spatial situations: the spatial deixis. Our main purpose is to describe the structure and use of the demonstrative system in small-scale space in the language spoken by Gypsies in Chile: the rromané jorajané. Data collection was performed with "The 1999 Demonstrative Questionnaire: 'THIS' and 'THAT' in comparative perspective” (Wilkins, 1999). The analysis results highlight that spatial demonstratives in rromané jorajané are a highly symmetrical group combining a deictic semantic component (the proximal-distal distinction) with grammatical contents (gender and number). It is a binary demonstrative system in terms of the category of distance from the deictic center. Additionally, it is concluded that choice of the suitable demonstrative proceeds according to the following pattern: the proximal demonstrative has its focal area in the speaker's zone of proximity, while the distal demonstrative includes both the addressee's zone of proximity and the speaker's distal zone within its application field.

Key words: Static location; spatial deixis; demonstratives; rromané spoken in Chile. 


\section{INTRODUCCIÓN}

Este trabajo estudia la localización de entidades en situaciones estáticas mediante los deícticos espaciales utilizados por hablantes de rromané jorajané de Chile ${ }^{1}$. Nuestro objetivo principal es describir la estructura del sistema demostrativo de esta lengua y su uso en la referencia espacial exofórica (Bohnemeyer, 2012).

El texto se articula en tres partes. La primera desarrolla la discusión del marco teórico, intentando presentar el problema de los demostrativos en relación con fenómenos más generales como el señalamiento gestual (el acto de apuntar con el dedo), la dependencia contextual de los contenidos "indexicales" y los interesantes vínculos de nuestro tema con teorías que reconocen bases gestuales en el desarrollo de la comunicación humana (Corballis, 2012; Tomasello, 2013). Junto con ello, se abordan algunos tópicos centrales de la descripción semántica de los demostrativos. La segunda parte corresponde al marco metodológico, donde se exponen algunas consideraciones acerca del trabajo de campo para la descripción semántica, y se discuten las ventajas y dificultades del método de elicitación utilizado, el cuestionario this and that (Wilkins, 1999).

La tercera parte corresponde al análisis de los datos, el que se organiza en función de una escala de "dominios de acceso espacial" (Wilkins, 1999). En esta entrega, el análisis se acotará al dominio de acceso de escala menor. Las respuestas que presentan mayor coincidencia (lo que ocurre en la mayoría de los casos) son las consideradas "por defecto" para la descripción, asumiendo que representan casos de uso prototípico de la expresión espacial en cuestión; las respuestas menos coincidentes son tratadas en segundo plano y se procura para ellas algún tipo de motivación de acuerdo con los parámetros generales del subdominio espacial correspondiente. Junto con lo anterior, se relevan como conclusiones del trabajo algunos aspectos prominentes del marco teórico y metodológico utilizado, y se hace hincapié en las afirmaciones que nos parecen más robustas en el análisis presentado.

En una publicación consecutiva se abordará el análisis del uso de los demostrativos en los dominios de acceso de escala media y distal. A partir de ello se propondrá una imagen general de la conceptualización deíctica del espacio, que integre los diversos elementos analizados de acuerdo con una estructuración prototípica del dominio en cuestión.

\footnotetext{
${ }^{1}$ En Lizarralde y Salamanca (2017) presentamos el marco teórico de nuestra investigación acerca de la localización espacial, abordando algunos tópicos centrales de la cognición espacial y la semántica de las expresiones espaciales. Para la escritura de los datos en rromané utilizamos la propuesta grafémica de Salamanca y Lizarralde (2008). Dicha escritura va siempre en cursiva. 240 | AlPha No49 (Diciembre 2019) PÁGS. 239-259. ISSN 07 16-4254
} 


\section{LA DEÍXIS ESPACIAL}

\subsection{EL SEÑALAMIENTO: BASES GESTUALES DE LA COMUNICACIÓN HUMANA}

La localización de entidades en el espacio es una actividad básica en la experiencia interactiva de los seres humanos; y para llevarla a cabo la estructura sociocognitiva propia de la especie cuenta con diversos recursos comunicativos. El más elemental de estos consiste en el gesto de señalar o apuntar aquello que ocupa la atención del comunicador. Aunque sencillo a simple vista, el señalamiento parece guardar en sí el germen de la comunicación intencional y cooperativa que realizamos mediante el lenguaje. Aquí hay dos puntos importantes de destacar:

i. Señalar con fines comunicativos específicos es un gesto exclusivamente humano (Cyrulnik, 2004; Tomasello, 2013). No existe entre las especies animales, no obstante los sofisticados sistemas de comunicación que algunas de ellas poseen, algo equivalente al acto de apuntar con el dedo hacia una entidad espacial o hacia un lugar, con el fin de orientar la atención del receptor. Esto no niega la relevancia de la gestualidad en la comunicación animal: al observar las prácticas comunicativas de primates en cautiverio, Tomasello (2013, pp. 26-33) identifica el productivo uso de la modalidad gestual en la interacción entre los grandes antropoides a partir de dos tipos de gestos: los movimientos de intención y los llamados de atención $n^{2}$. Y si bien estos últimos se relacionan con el señalamiento en cuanto a su capacidad de orientar la atención del receptor, ambas formas de gestualidad son fundamentalmente diádicas, pues buscan influir de forma directa en el destinatario, sin comunicar algo sobre alguna tercera entidad. En esto difieren del carácter triádico del señalamiento humano, dado por su naturaleza referencial (referir a una entidad distinta del emisor y el receptor).

ii. Esta estrategia no espera al desarrollo del lenguaje hablado. Son evidentes los usos del señalamiento en la comunicación cara a cara, acompañando expresiones como mira eso, pero acá lo notable es la abundante evidencia de un uso complejo del señalamiento en niños prelingüísticos. Sobre esto, encontramos afirmaciones bien enfáticas en autores como William Stokoe, quien observa el fenómeno desde su análisis del desarrollo de las lenguas de señas: "Todos los infantes, sordos o no, se comunican al

\footnotetext{
${ }^{2}$ Los movimientos de intención corresponden a la manifestación abreviada de una conducta completa, que producen en el receptor una respuesta equivalente a la que produciría dicha conducta (como la cría que toca el lomo de su madre para que esta la cargue). Por tratarse de actividades habituales, están altamente ritualizados y tienen un "significado" que está contenido en la acción misma. Los llamados de atención, por su parte, son acciones que tienden a dirigir la atención del receptor hacia el comunicador (como dar un empujón o lanzarle un objeto a otro individuo), las que explotarían un efecto secundario de actividades que naturalmente llaman la atención de un eventual receptor, de modo que tendrían el mismo carácter ritualizado de los movimientos de intención. La intención comunicativa de estos llamados no está en la acción misma, sino "en la exteriorización involuntaria, que el individuo actuante sabe que el receptor debe advertir para reaccionar como corresponde" (Tomasello, 2013, p. 31).
} 
principio por medio de señas" (2004, p. 57). A los 12 meses los infantes señalan abundantemente y lo hacen con motivos comunicativos diversos, que van más allá de la naturaleza puramente impositiva (en el sentido de la petición de obtener algo que se desea) que tradicionalmente se le ha atribuido a esta conducta (Farkas, 2007; Tomasello, 2013).

El señalamiento manifestaría una actitud cooperativa que sería universal y constituiría uno de los prerrequisitos para el desarrollo del habla, lo que implica de por sí una teoría acerca de la ontogenia del lenguaje y, desde allí, también una propuesta de explicación de su filogénesis. El acto de señalar, desde este punto de vista, "fue la forma primordial de comunicación específicamente humana” (Tomasello, 2013, p. 14). Esta naturaleza fundacional del componente gestual es enfatizada también en Corballis (2012, p. 382), para quien "el lenguaje es gestual", en la medida en que requiere el uso del cuerpo para transmitir información de un individuo a otro. Para este autor, el uso del tracto vocal para producir sonidos sería una forma más de usar el cuerpo para producir mensajes perceptibles, lo mismo que el uso de los brazos o el rostro para generar estímulos comunicativos visuales. $\mathrm{Y}$ en cuanto a la predominancia de una $\mathrm{u}$ otra de estas modalidades, sostiene que "el lenguaje evolucionó, en sus etapas iniciales, a partir de gestos manuales y los elementos vocales se sumaron de forma gradual, haciéndose dominantes solo en una etapa posterior de la evolución de nuestra especie" (Corballis, 2012, p. 383. Nuestra traducción, en adelante N.T.) ${ }^{3}$.

Más allá de su función referencial (orientar la atención hacia una entidad o lugar), la gestualidad tiene una motivación prosocial, en el sentido de que estos actos ostensivos "se proponen conseguir que el receptor infiera la intención social del comunicador: lo que éste quiere que el receptor haga, sepa o sienta" (Tomasello, 2013, p. 54). De modo que, desde esta perspectiva cooperativa de la comunicación, más que una tendencia innata a desarrollar lenguaje (en el sentido generativista de la afirmación) lo que habría es "un impulso genéticamente determinado, pero es un impulso de percibir-y-actuar, no de crear un lenguaje conforme a reglas universales y genéticamente determinadas" (Stokoe, 2004, p. 56).

\footnotetext{
${ }^{3} \mathrm{El}$ argumento de Corballis a favor de una teoría gestual del origen del lenguaje es muy sugerente. Desde una mirada evolutiva, los gestos corporales de los grandes simios, en comparación con sus sistemas de llamadas, son más cercanos al lenguaje: por un lado, estas gesticulaciones se desarrollan a partir de aprendizaje social y, por otro, requieren de la atención del receptor. Esto, junto con el hecho de que solo ha habido avances significativos en el aprendizaje comunicativo de primates a partir de estímulos visuales, le permite al autor hipotetizar que, en etapas tempranas de la evolución, los homínidos habrían estado mejor adaptados para el desarrollo de un "sistema de comunicación intencional y adaptable, basado en gestos manuales, que en uno basado en llamadas vocales" (Corballis, 2012, p. 383.N.T.).
}

242 | Alpha No49 (Diciembre 2019) PÁGS. 239-259. ISSN 07 16-4254 


\subsection{SEÑALAR CON PALABRAS: LOS DEMOSTRATIVOS}

El señalamiento tiene su manifestación lingüística más directa en el fenómeno de la indexicalidad, entendida como la capacidad de determinadas construcciones o ítems léxicos para individualizar entidades accesibles en el contexto de habla (Hanks, 2009, p. 10). Así descrita, la indexicalidad bien podría homologarse al fenómeno general de la referencia; sin embargo, el problema aquí se centra en unidades que realizan la referencia deíctica. Expresiones de este tipo establecen una relación existencial entre un objeto de referencia y un origo (o centro deíctico), el "yo-aquí-ahora" del hablante (Bühler, 1961[1934]), que funciona como la base indexical a partir de la cual se establece dicha relación. De modo que no es posible identificar los referentes de estas expresiones "directamente a partir de ningún código y deben inferirse del terreno conceptual común" (Tomasello, 2013, p. 51).

Lo anterior se instancia de manera privilegiada en los demostrativos espaciales, de modo que estos debieran ser un punto de partida obligado al estudiar el fenómeno de la localización y el mapeo entre lenguaje y espacio (Coventry, 2015: 409). Se trata, además, de un fenómeno universal, debido a que todas las lenguas del mundo tienen formas demostrativas (Hanks, 1992; Diessel, 1999, 2006a, 2006b; Lenz, 2003), lo que deja fuera de discusión su centralidad en la reflexión lingüística. Estas expresiones son intrínsecamente deícticas, pues la comprensión de su significado "invoca" características del contexto, debido a que una variable contextual está incorporada en sus condiciones semánticas (Levinson, 2004). Tal es el caso el adverbio locativo en ahí está la casa o el pronombre demostrativo en esa es la casa. La característica distintiva de los demostrativos espaciales, cuando se usan para referir/localizar un objeto, es que "anclan" su significado en parámetros concretos de la situación de habla de acuerdo con una perspectiva egocéntrica. De modo que constituyen una subcategoría (distinta de los demostrativos de tiempo y persona) que "típicamente codifica el ego del hablante en relación con aspectos espaciales del contexto de habla, desde el punto de vista del hablante" (Wu, 2004, p. 3. N.T.). Estos aspectos espaciales se manifiestan en términos de distancias relativas (cercanía o lejanía) entre aquello señalado y el lugar ocupado por el hablante o el oyente en una situación canónica de interacción cara a cara (Lyons, 1989[1977]). Siendo inseparable de su contexto inmediato, el significado de las expresiones demostrativas se ubica en el límite siempre difuso entre las dimensiones semántica y pragmática.

La tradición gramatical ha incluido los demostrativos entre los denominados elementos de clases cerradas o de función gramatical (opuestos a los elementos nocionales o de clase abierta). Estas unidades poseen un significado muy esquemático, actuando como una suerte de "soporte" para establecer las relaciones entre elementos de clase abierta. Para Diessel (2006a) la caracterización de los demostrativos no puede reducirse a una función puramente gramatical y aboga por una categoría que, más allá de 
esta dicotomía, ponga en primer plano su función comunicativa fundamental, que consistiría -en sus usos básicos- en coordinar el foco de atención conjunta de los interlocutores.

Por supuesto, los demostrativos pueden desempeñar diversas funciones en la lengua y esto hace complejo su análisis. Entre los diversos usos de los demostrativos (ver Levinson, 2004, pp. 107-109), nuestro foco de atención está en el llamado uso exofórico, a partir del cual se realiza la referencia espacial exofórica, que corresponde al uso de los demostrativos "para referir a objetos o eventos, reales o imaginarios, presentes en el espacio en el momento de habla" (Bohnemeyer, 2012, p. 100. N.T.). Hay buenas razones para considerar la función exofórica como la más básica de los demostrativos. En primer lugar, es la más directamente relacionada con el señalamiento gestual, y si este acto constituye un prerrequisito de la comunicación linguística, entonces es esperable que todas las lenguas puedan incorporar en su gramática, de algún u otro modo, la función del señalamiento (Cairns, 1991, p. 19). Comúnmente, el uso exofórico de un demostrativo va acompañado del gesto de apuntar $\mathrm{y}$, aunque se trate de dos dinámicas distintas (verbal y gestual, respectivamente), su relación es tan estrecha que es posible afirmar que el uso prototípico de los demostrativos espaciales implica el gesto de apuntar (Levinson, 2004; Diessel, 2006a).

Además, y aunque en principio su uso suele ser problemático debido a su dependencia deíctica, los demostrativos aparecen tempranamente durante el proceso de adquisición del lenguaje, siendo el único tipo de términos no nocionales que los niños utilizan durante la etapa de "una palabra". En este contexto de uso temprano de los demostrativos, se produce una notable sinergia entre palabra y gesto, lo que "crea una poderosa herramienta que permite al infante referir a cualquier entidad en el entorno sin conocer la palabra para nombrar aquello referido" (Diessel, 2006a, p. 472. N.T.). Por ejemplo, una acción puede ser referida mediante la palabra (el verbo "dame"), mientras un objeto es señalado gestualmente.

\subsection{SEMÁNTICA DE LOS DEMOSTRATIVOS}

La semántica de los demostrativos incluye tanto el componente deíctico como características cualitativas (Diessel, 1999). Las características cualitativas corresponden a contenidos gramaticales o semánticos, aislables o no morfológicamente, que permiten caracterizar al referente, así como el género, el número o la ontología. Estas pueden permitir emparentar las formas demostrativas con otras clases de palabras o concebirlas como parte de paradigmas más amplios e inclusivos. Así, por ejemplo, la distinción ontológica entre una locación o una entidad corresponde a una caracterización cualitativa del referente, que en muchas lenguas se corresponde directamente con la distinción categorial entre adverbios y pronombres demostrativos: los adverbios 
demostrativos solo pueden referir a un lugar (aquí, ahî), mientras que los pronombres/adjetivos demostrativos se usan para indicar personas u objetos.

Por su parte, las características deícticas tributan a la función de localizar un objeto en relación con el centro deíctico. Los demostrativos suelen contrastar en cuanto a la distancia relativa que establecen entre aquello indicado y la posición del hablante, el oyente $\mathrm{u}$ otro elemento tomado como punto de referencia deíctica. En español, por ejemplo, "los demostrativos permiten realizar divisiones en el espacio (o, más exactamente, en la distancia) que separa el hablante del referente" (RAE, 2010, p. 330). Es necesario destacar el carácter relativo de estas divisiones. Así, lo que se concibe como próximo o distante siempre dependerá de cómo el hablante perciba la distancia en una situación particular (Wu, 2004).

$\mathrm{Al}$ abordar este contenido se debe considerar: la cantidad de contrastes de distancia establecidos, los conjuntos de unidades (subsistemas) que portan este valor y el Pivot (Hablante-Oyente) en torno al cual se articula la distancia (Fillmore, 1982). Respecto del primer asunto, los sistemas demostrativos suelen presentar dos o tres contrastes en la distancia. Diessel (2006b, p. 431), en su empeño por proporcionar una imagen general de la situación de los demostrativos en las lenguas del mundo, constata la predominancia de los sistemas con dos contrastes de distancia (más del 50\% del repertorio de las lenguas consideradas en su estudio), seguidos de aquellos que presentan tres (poco más de un tercio del total). En el caso de las lenguas cuyos demostrativos no contrastan en la distancia (menos del 3\%), estos elementos suelen unirse de todos modos con adverbios espaciales. Como en los demostrativos dies y das del alemán, los que pueden ser utilizados con sentido proximal o distal; para indicar un uso contrastivo, se acompañan del adverbio demostrativo da "aquí": das $d a$ "este/ese aquí" (el ejemplo es de Diessel, 1999). Por su parte, los sistemas demostrativos con más de tres contrastes son muy poco comunes y relativamente "extraños". Así, es posible sostener que el contraste próximo/distante es subyacente a los sistemas demostrativos de las lenguas del mundo (Diessel, 1999; 2006b). Estas observaciones derivadas de la descripción tipológica tendrían también un correlato en los hallazgos de la neurociencia, que aportaría evidencia de la existencia de sistemas cerebrales diferentes para representar el espacio cercano (la dimensión peripersonal) y el distante (extrapersonal) (Coventry, 2015).

Un sistema de dos contrastes, como el del inglés (o como el que aquí describiremos para el rromané), se puede representar del siguiente modo:

D/[+Proximal] "relativamente cercano al Hablante"

D/[-Proximal] "relativamente distante del Hablante"

Un sistema de tres contrastes, como el del español, se representaría como sigue:

D/[Proximal], D/[Medial], D/[Distal]

El valor específico de cada contraste es un asunto discutible. El valor deíctico asignable a la categoría medial, podría caracterizarse como aquello localizado a una 
pequeña distancia del hablante o que está relativamente cercano al oyente. Por su parte, el rasgo distal codificaría aquello ubicado a gran distancia tanto del hablante como del oyente, o bien, aquello que está fuera del campo visual de los interlocutores (Fillmore, 1982). Estas últimas características pueden co-ocurrir (las cosas lejanas pueden ser relativamente difíciles de ver). Pero es importante atender a la eventual emergencia de la visibilidad como un contenido cubierto por un sistema demostrativo bajo estudio (Wilkins, 1999). Algunas lenguas pueden lexicalizar este contraste, con lo que se obtiene el par: D/[+Visible], opuesto a D/[-Visible].

Se trata de un rasgo que ha generado bastante atención, en particular en el trabajo con lenguas no indoeuropeas (como en algunas lenguas indígenas de Norteamérica). La visibilidad es, de suyo, una característica deíctica, pues hablamos de aquello visible para el hablante desde su particular ubicación espacial al momento de habla (Levinson, 2004). La visibilidad debiera ser tomada en cuenta aun cuando no estemos frente a una lengua que haga una distinción explícita de este parámetro. En investigaciones experimentales del uso de los demostrativos del inglés, se ha observado que los hablantes pueden ser sensibles a este factor y también a otros, como la familiaridad con el objeto localizado, lo que sugiere que la selección de un demostrativo (en lenguas como el inglés o el español) puede estar motivada no solo por las distancias relativas, sino por aspectos "extraperimetrales" (no espaciales) relacionados con la naturaleza de los objetos (Coventry, 2015).

En relación con el pivot que articula la distancia, Diessel (1999) sostiene que los sistemas demostrativos de tres contrastes suelen ser "orientados a la persona", de modo que el D/[Medial] corresponderá al contenido "relativamente cercano al oyente", en oposición al D/[Proximal], que especifica lo "relativamente cercano al hablante", y ambos opuestos al D/[Distal], que se utilizará para localizar objetos distantes a ambos. Los sistemas de dos contrastes, en cambio, estarían regularmente "orientados a la distancia".

Estos son algunos de los criterios que orientan el análisis que proponemos de los datos recogidos, aplicando la metodología que se describe a continuación.

\section{MARCO METODOLÓGICO}

\subsection{TRABAJO DE CAMPO PARA EL ANÁLISIS SEMÁNTICO}

El trabajo de campo en semántica es complejo, sobre todo al ocuparse de lenguas poco estudiadas. Resolver problemas relativos al significado de las expresiones de una lengua depende en gran medida de las intuiciones de los propios hablantes, pero -en general- los lingüistas de campo no son hablantes nativos de la lengua que estudian, de modo que no pueden echar mano a su propia intuición de hablante. Descripciones morfológicas o sintácticas disponibles pueden aportar de forma muy limitada a este 
interés. Ante esto, el investigador de campo tendrá las opciones de inferir el significado de una expresión a partir de la observación de su uso en contexto o de elicitar juicios sobre la aceptabilidad de enunciados en contextos particulares. Ambas modalidades de trabajo entrañan dificultades. Así, junto con el problema de la ausencia de datos apropiados, se presentan las dificultades de desarrollar un análisis del contenido semántico (intensión), basado en un corpus de datos (extensión), sean estos observados o elicitados (Hellwig, 2006).

En los últimos años, se ha discutido acerca de este desafío metodológico en estudios semánticos de orientación tipológica (Levinson y Wilkins, 2006). Trabajos de este tipo requieren datos que sean comparables, lo que precisa de un método estándar para su recolección. Bohnemeyer (2012) reflexiona acerca del estudio empírico de la deíxis espacial, a partir de una comparación entre la metodología usada por Hanks (1992) (basada en grabaciones de habla espontánea) y el uso que él mismo hace del cuestionario this and that para la elicitación de datos del sistema demostrativo del Maya Yucateco. La base de dicha comparación está, precisamente, en la ausencia de técnicas estandarizadas para describir la forma y significado de los demostrativos espaciales. La discusión apunta a que cada acercamiento (habla espontánea vs. datos elicitados) permite "capturar" dimensiones distintas de la compleja organización semántica de los demostrativos y su uso. Urge, pues, contar con una metodología que permita delimitar parámetros interaccionales del contexto de habla en el que estas formas son usadas, considerando la locación de los participantes y de los objetos de referencia dentro de espacios reales y sociales relevantes (Bohnemeyer, 2012, p. 100). El cuestionario que se describe a continuación es un aporte en este sentido.

\subsection{LOS DATOS}

Datos iniciales fueron obtenidos de relatos tradicionales recogidos en Salamanca (2002) y de la traducción al rromané del Nuevo Testamento (Sociedad Bíblica Chilena, 2007). La elicitación directa de los datos para nuestra investigación se articuló a partir de una herramienta ya clásica en la descripción de la localización espacial deíctica en lenguas naturales: el Demonstrative Questionnaire: 'THIS' and 'THAT' in comparative perspective, de D. Wilkins (1999). Se trata de un estímulo de elicitación no verbal desarrollado en el Instituto Max Planck de Psicolingüística de Nimega, Holanda ${ }^{4}$. Estímulos de este tipo son habituales en el trabajo de campo orientado a la semántica, pues crean contextos controlados que hacen posible elicitar una muestra abundante del tipo de expresión que se busca describir (Hellwig, 2006; Levinson y Wilkins, 2006).

\footnotetext{
${ }^{4}$ Este material y otros relativos a diversos dominios semántico/cognitivos son de acceso libre en el sitio web http://fieldmanuals.mpi.nl/ (Departamento de Lenguaje y Cognición, MPI).
} 
El cuestionario this and that nos ayudará a identificar el rango de uso de las formas demostrativas de la lengua estudiada, en relación con tres parámetros fundamentales. En primer lugar, en cuanto al anclaje que presentan los términos demostrativos: si se trata de un sistema anclado en el hablante, en el oyente, en el hablante y el oyente, o bien, presenta un centro deíctico anclado en un elemento distinto a los participantes del evento de habla. En segundo lugar, el cuestionario permite determinar cuáles son las distinciones de distancia contenidas en el sistema estudiado, rasgo que -como recordaremos-constituye una de las principales características de los sistemas demostrativos. En tercer lugar, esta herramienta debiera ser capaz de evidenciar si el rasgo de "visible vs. no visible" es un criterio pertinente.

Junto con lo anterior, el cuestionario controla también una variable interaccional, en la medida en que las escenas diagramadas apuntan a diferenciar entre diversos dominios de acceso: de escala menor, que incluye el espacio personal y el de la interacción cara a cara; de escala media, los espacios del hogar y pequeñas trayectorias cotidianas, y de gran escala, distancias de gran amplitud. Es importante reconocer estos dominios, pues permitirían identificar restricciones que pueden ser cruciales en el uso de las expresiones demostrativas (Wilkins, 1999).

En concreto, se trata de un set de 25 escenas que configuran escenarios de elicitación en que los colaboradores deben referir a un objeto particular. Dichos escenarios contrastan sistemáticamente en cuanto a la ubicación del objeto de referencia en los distintos dominios de acceso recién descritos. Así, el cuestionario sugiere generar instancias de "señalamiento verbal" a referentes que pueden ser partes del cuerpo del colaborador y el entrevistador, objetos en contacto con sus cuerpos, ubicados en el espacio circundante, o bien a amplia distancia de ambos (en nuestro caso, edificios o cerros visiblemente lejanos).

Datos así obtenidos permitirán una evaluación de la semántica de los demostrativos, determinando sus características relacionales, las que apuntan a especificar "la relación entre el objeto de referencia y el contexto de habla particular donde toma lugar el acto" (Hanks, 1992, p. 50. N.T.). Además, permiten conseguir evidencia negativa relativa a usos de las formas demostrativas que no son aceptables para los hablantes en contextos particulares (Bohnemeyer, 2012).

\subsection{LOS COLABORADORES}

En la elicitación de los datos y posterior chequeo de la información participaron tres colaboradores, todas mujeres gitanas adultas, bilingües rromanélespañol ${ }^{5}$. Una de las

\footnotetext{
${ }^{5}$ De acuerdo con los principios clásicos para este tipo de trabajos, en cuanto a edad de los colaboradores y conocimiento de la lengua de contacto (Samarin, 1967, p. 61-64).

248 | Alpha No49 (DiCIEMBRe 2019) PÁGs. 239-259. ISSN 07 16-4254
} 
entrevistas tuvo como escenario el domicilio de la participante, en la comuna de San Pedro de la Paz; mientras que las entrevistas con gitanos nómades se realizaron en dos campamentos tradicionales: uno en Talcahuano y el otro en el sector de "Cosmito", camino a la comuna de Penco.

Aunque el número de la muestra es reducido, los datos obtenidos son suficientemente significativos, si consideramos el alto grado de convergencia (Bohnemeyer, 2012) que muestran las colaboradoras en sus respuestas. Además, las recomendaciones dadas por el propio autor del material sugieren contar con cinco informantes como una cantidad suficiente y considera que tres es el número mínimo para realizar análisis con el tipo de datos que arroja el cuestionario (Wilkins, 1999). Muestras de esta magnitud son habituales en las investigaciones en que se ha utilizado este material, por ejemplo, Bohnemeyer (2012) describe el sistema demostrativo del yucateco a partir de las respuestas de cinco hablantes.

A propósito de los colaboradores que participaron en esta investigación, y en relación con las características del modus vivendi de la etnia gitana que habita en Chile, nos parece que nuestra muestra, aunque pequeña, logra abarcar la diversidad de las formas del nomadismo de los rromá de nuestro país. Esto no se planteó como un objetivo metodológico de la investigación, sino que se dio como una condición del trabajo de campo. Y aunque no es una variable considerada en el análisis, nos parece que esta afortunada articulación de la procedencia de los datos confirma que la lengua gitana hablada en Chile presenta un alto grado de vitalidad (Salamanca, 2005).

\section{ANÁLISIS}

\subsection{DEÍXIS ESPACIAL EN EL ROMANÉ JORAJANÉ: EL SISTEMA DEMOSTRATIVO}

El primer paso al estudiar la deíxis espacial en una lengua es describir el paradigma en que organizan los demostrativos. Estos constituyen en rromané un subsistema finito, altamente simétrico y binario en cuanto a la proximidad del centro deíctico, como se aprecia en los siguientes ejemplos (todos en caso nominativo):

$\begin{array}{llll}\begin{array}{l}\text { Gavá chavrró } \\ \text { Este muchacho }\end{array} & \text { Gua (gová) chavrró } & \text { Gayá riat } & \text { Goyá riat } \\ \text { Ealá minonorré } & \text { Golá minonorré } & \text { Galá esgóde } & \text { Golá esgóde } \\ \text { Estos pequeñitos } & \text { Esos pequeñitos } & \text { Estas cosas } & \text { Esas cosas }\end{array}$

En Tabla 1 presentamos nuestra propuesta de segmentación morfológica de los demostrativos del rromané jorajané ${ }^{6}$ (Lizarralde y Salamanca, 2010):

\footnotetext{
${ }^{6}$ Aunque poco estudiada, la lengua gitana cuenta con algunas descripciones morfosintácticas pioneras que orientan nuestro trabajo (Salamanca, 2006; González y Salamanca, 2011; por ejemplo).
} 
Tabla 1

\begin{tabular}{|c|c|c|c|}
\hline & Masculino (sing.) & Femenino (sing.) & Plural \\
\hline Proximidad & g... - a - v- Ø-...á & g... - a-y-ø-...á & g... -a- Ø-1-...á \\
\hline Apartamiento & g... - o-v-Ø-...á & g...-o-y-ø-...á & g...-o- $\varnothing-1-\ldots a ́$ \\
\hline
\end{tabular}

La estructura morfológica de estas unidades puede ser representada a partir de una raíz discontinua "g-... ...-á". Flanqueados por esta raíz, se presentan -de acuerdo con nuestra interpretación- el morfema de distancia y la flexión de género y número, con sus respectivos morfemas instanciadores; tal como se muestra en la Tabla 2:

Tabla 2

\begin{tabular}{|l|c|c|c|c|}
\hline \multicolumn{4}{|c|}{ Raíz } \\
\cline { 2 - 4 } & Distancia & Género & Número & \\
\hline g... & $\begin{array}{c}\text { morf. de } \\
\text { distancia }\end{array}$ & $\begin{array}{c}\text { morf. de } \\
\text { género }\end{array}$ & $\begin{array}{c}\text { morf. de } \\
\text { número }\end{array}$ & ...á \\
\hline
\end{tabular}

Esta fórmula se puede completar con una forma concreta; por ejemplo, gavá, este (D/[+Prox.+masc.+sing.]), con lo que obtenemos la Tabla 3:

Tabla 3

\begin{tabular}{|c|c|c|c|c|}
\hline \multicolumn{4}{|c|}{ Raíz } \\
\cline { 2 - 4 } & Proximidad & masculino & singular & \\
\hline g... & $\mathrm{a}$ & $\mathrm{v}$ & $\varnothing$ & ...á \\
\hline
\end{tabular}

Según la descripción translingüística que Diessel (1999) hace de la morfología de los demostrativos, estas unidades se ubican entre dos extremos: por un lado, está el caso de lenguas cuyas formas demostrativas son invariables, como los determinantes $i, k u, c e$, del Coreano, que expresan distintos grados de distancia y no aceptan ningún tipo de modificación (el ejemplo es tomado de Diessel, 1999, p. 20); por otro lado, tenemos lenguas con sistemas demostrativos flexionales, cuyas raíces incorporan diversas clases de morfemas, típicamente género, número o marcas de caso. Esto último es lo más habitual: de las 85 lenguas consideradas en Diessel (1999), 68 presentan flexión en estas formas. Y este es también el caso del rromané, que posee un sistema que utiliza una raíz demostrativa a la que se agregan morfemas gramaticales de género y número.

En cuanto a sus características sintácticas, se recomienda distinguir entre el uso de un demostrativo en un contexto sintáctico específico y su estatus categorial. Los contextos sintácticos particulares en los que se desplegarán los elementos constitutivos de un sistema demostrativo determinarán la categoría léxica de la que formarán parte. 
Las dos primeras categorías corresponden a los demostrativos que funcionan como pronombres y como determinantes: los primeros se presentan como un pronombre independiente en la posición de argumento de un verbo (ese tiene mal olor), mientras que los últimos típicamente determinan al nombre en una frase nominal (ese calcetín tiene mal olor). El principal motivo para tratarlos en conjunto es su estrecho vínculo formal: en la mayoría de las lenguas estudiadas, las mismas formas demostrativas funcionan como pronombres independientes y como modificadores nominales (Diessel, 1999, p. 59). Esto es así en rromané, donde las formas demostrativas pueden funcionar como pronombres o como determinantes nominales. Por cierto, como se señaló en la descripción metodológica, los datos para esta investigación se centran en demostrativos que funcionan como determinantes en frases nominales, cuyo núcleo corresponde al sustantivo que nombra al objeto localizado. Sin embargo, aunque aislados, los datos permiten corroborar la existencia de usos pronominales de los demostrativos, como en el siguiente ejemplo de nuestra muestra: goyá si múrrni esa es mía.

La tercera categoría corresponde a los adverbios demostrativos, los que sintácticamente funcionan como modificadores verbales que aportan un valor locativo, relativo a una región espacial. De esta forma, completan el sistema demostrativo del rromané los adverbios locativos katé y koté, como en: katé si mo chavrró (aquí está mi hijo), en contraste con koté si mo chavrró (allí está mi hijo). La coincidencia con los pronombres/determinantes demostrativos no solo está en el contraste de distancia establecido, sino también en una semejanza formal difícilmente atribuible a una mera homofonía: las unidades "- $a$ " y " $-o$ ", que fueron descritas como los morfos instanciadores de la categoría deíctica de distancia, aparecen también en las formas adverbiales y vinculadas al mismo contraste. Esto, a nuestro juicio, configura un sistema demostrativo sumamente consistente a nivel semántico y morfológico.

Así las cosas, adoptando las consideraciones morfológicas y sintácticas que propone Diessel (1999) para la descripción general de los sistemas demostrativos en lenguas naturales, por un lado, y los datos recogidos en nuestro trabajo de campo, por otro, podemos tabular el sistema demostrativo espacial del rromané tal como sigue en la Tabla 4:

Tabla 4. Demostrativos espaciales del rromané jorajané de Chile

\begin{tabular}{|l|c|c|c|c|c|}
\cline { 3 - 6 } \multicolumn{1}{c|}{} & \multicolumn{3}{c|}{ Próximo } & \multicolumn{2}{c|}{ No-próximo } \\
\cline { 3 - 6 } \multicolumn{1}{c|}{} & & Masc. & Fem. & Masc. & Fem. \\
\hline \multirow{2}{*}{ Referencia a entidades } & Singular & gavá & gayá & gová (wa) & goyá \\
\cline { 2 - 5 } & Plural & \multicolumn{2}{c|}{ galá } & \multicolumn{2}{c|}{ golá } \\
\hline Referencia a lugares & & \multicolumn{2}{c|}{ katé } & \multicolumn{2}{c|}{ koté } \\
\hline
\end{tabular}




\subsection{USOS DEMOSTRATIVOS EN EL RROMANÉ JORAJANÉ}

Los datos muestran que los demostrativos de la lengua gitana son sensibles a las características locativas establecidas en las escenas diagramadas en el cuestionario: estas formas contrastan a partir de la localización del objeto de referencia en relación con los participantes del acto comunicativo. Será relevante considerar y distinguir los diversos dominios de acceso espacial subyacentes a las escenas del cuestionario, pues la estructura general del sistema demostrativo del rromané sugiere, de acuerdo con nuestra interpretación, características directamente relacionadas con tales dominios espaciales.

\subsubsection{ESPACIO DE ESCALA MENOR}

Las primeras doce escenas del cuestionario plasman localizaciones relativas a un espacio de escala menor, que incluye los dominios del espacio personal y el de la interacción (esto último, en un sentido restringido de interacción cercana, prototípicamente la conversación "cara a cara"). En los datos relativos a estas escenas se puede observar de manera muy sistemática cómo la cercanía con el hablante o con el oyente determina la selección del demostrativo proximal y distal, respectivamente. Para empezar, veremos dicho contraste en las escenas (1) y (2), en las que el objeto referido es una parte del cuerpo:

(1)

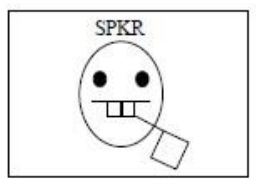

gavá dam mínmo si kaló

'este diente mío está negro'

gavá dan dukhál ma

'este diente me duele'
(2)

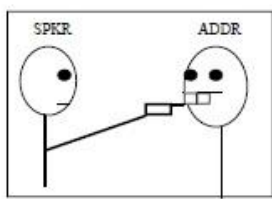

guá dan chíro si kaló

'ese diente tuyo está negro'

Guá dan dukhál tu

'ese diente te duele'

Las escenas (3), (4) y (5) , por su parte, toman como referente un objeto en contacto con el cuerpo del hablante o del oyente ${ }^{8}$ :

\footnotetext{
${ }^{7}$ Las escenas (4) y (5) son prácticamente idénticas, con la única diferencia de que en la primera el hablante debe apuntar al objeto referido. Debido a que no hemos encontrado diferencias ante la ausencia o presencia del gesto mostrativo, trataremos estas escenas como una sola.

${ }^{8}$ Aunque la imagen propuesta en el cuestionario muestra un insecto, en la elicitación de nuestros datos utilizamos objetos inanimados (aros, un lápiz) en contacto con el cuerpo del hablante o del oyente, como lo muestran los enunciados transcritos.
}

252 | AlPHA No49 (DiciemBre 2019) PÁGS. 239-259. ISSN 07 16-4254 
(3)

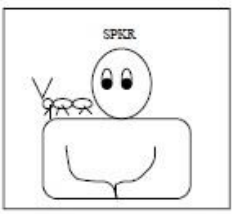

gayá chen si ćnde mo kan 'este aro está en mi oreja'

gavá lápiz si mínmo 'este lápiz es mío'
(5)

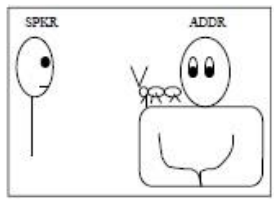

goyá chen si ánde cho kan 'ese aro está en tu oreja'

guá lápiz si chíro 'ese lápiz es tuyo'

Siempre dentro del dominio de acceso de escala menor, pero ahora contrastando escenas configuradas tanto en el espacio personal como en el de la interacción, las siguientes escenas se estructuran con un objeto de referencia "al alcance de la mano" del hablante y del oyente, respectivamente. Se apreciará nuevamente el contraste de la cercanía hablante/oyente en los siguientes pares de escenas:

(6)

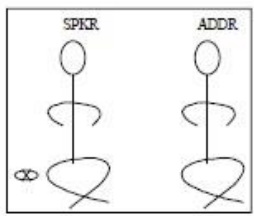

gayá jólva si mírmi 'esta botella es mía'

gayá métla si pása mánde 'esta escoba está a mi lado'

(7)

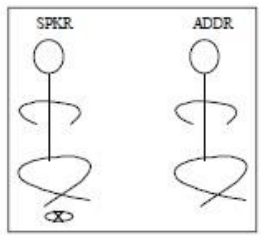

e jólva gayá si ángla mánde 'la botella esta está delante de mi'

gayá métla si ángla mánde 'esta escoba está delante de mí'
(10)

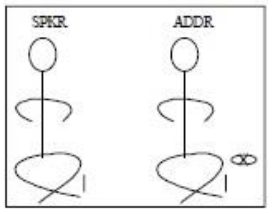

goyá botella si pása túte 'esa botella está al lado tuyo'

goyá métla si chíri 'esa escoba es tuya'

(9)

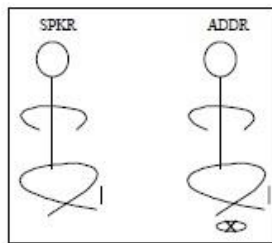

an ejólva goyá kai si ángla túte kai si múrmi 'pasa la botella esa que está delante de ti que es mía'

goyá métla si chín

'esa escoba es tuya' 
Las ocho escenas revisadas hasta aquí evidencian un contraste inequívoco entre la forma proximal y distal del demostrativo, relativo al acceso privilegiado al objeto de referencia por parte del hablante o del oyente, respectivamente. Lo anterior cuenta con el respaldo de que en estas escenas todas las respuestas, sin excepción, contrastan de este modo.

Las siguientes dos escenas bajo consideración, (8) y (12), muestran una variación respecto de las anteriores, pues en las dos el objeto de referencia se presenta equidistante a ambos interlocutores: al alcance de la mano de ambos, en la primera, y a algunos pasos frente a ambos, en la segunda. Al comparar los enunciados elicitados, encontramos que, en primer lugar, en (8) se rompe la coincidencia que hasta ahora presentaban los hablantes en la selección del demostrativo utilizado: en esta escena hay una preferencia por el demostrativo proximal, pero no un uso exclusivo de este. De modo que la proximidad respecto tanto de emisor como de receptor genera una situación en la que ambos demostrativos son aceptables:

(8)

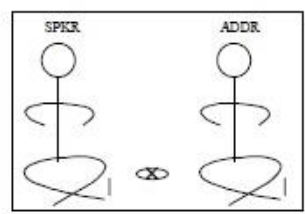

gayá métla si po maskarál améndar

'esta escoba está en medio de nosotros'

an ejólva goyá kai si múmi

'pasa la botella esa que es mía'

Atendiendo a los enunciados anteriores, nos parece que la situación configurada en (8) muestra que sendas localizaciones de hablante y oyente pueden ser utilizadas como el criterio determinante para la selección de la forma deíctica usada. De este modo, haciendo un análisis específico, relativo exclusivamente a las escenas observadas, los datos sugieren que la selección del demostrativo utilizado en cada caso está determinada por (usando la terminología aplicada por Bohnemeyer, 2012) la zona de proximidad relativa a cada uno de los participantes de la interacción. Podemos decir que el área focal del demostrativo de proximidad es indiscutiblemente la zona próxima al hablante, la que, de acuerdo con las escenas que dan pie a la selección de la forma proximal, correspondería al espacio ocupado por el cuerpo mismo del hablante (específicamente, partes del cuerpo), la zona de contacto con dicho cuerpo y el espacio al alcance de la mano del emisor.

Por su parte, y recalcamos que esto es solo aplicable a las escenas vistas hasta aquí, el demostrativo distal tendría como área focal la zona próxima al oyente, en los mismos dominios específicos que se mencionaron respecto del hablante. Frente a esto, la disponibilidad de ambas formas demostrativas en una escena como la número 8, que daría cuenta de una configuración espacial que es conceptualizada como "próxima a ambos sujetos", una suerte de "zona próxima de los interlocutores", que aunque no se manifiesta lingüísticamente en el uso de una forma específica en el sistema demostrativo de la lengua, instancia la posibilidad de usar ambos demostrativos. 
Limitándonos a la zona del espacio personal y de interacción que se dibuja en los contrastes descritos, se podría proponer el siguiente esquema, que recoge las zonas próximas de hablante y oyente, incluyendo el espacio equidistante entre ambos sujetos, figurado en la escena (8):

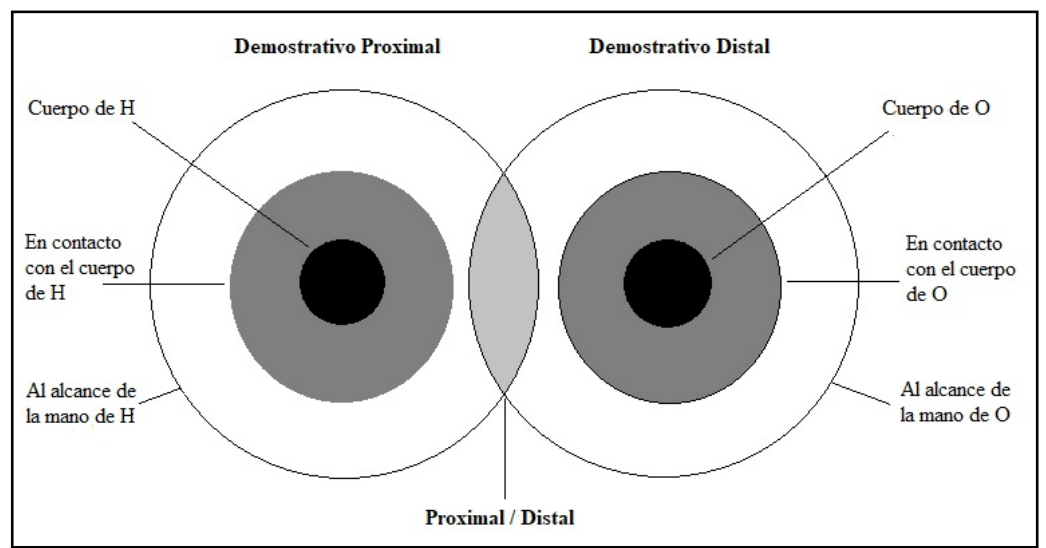

Figura 1: Configuración del pivot hablante/oyente en el espacio de menor escala

Con la escena (12) se mantiene la tendencia a la homogeneidad de las respuestas al estímulo; sin embargo, es fácil observar que el pivot hablante/oyente que hasta aquí determinaba el contraste del demostrativo escogido ya no está disponible como el criterio que gobierna dicha selección, porque el objeto de referencia se ubica "a pasos" de ambos interlocutores, de modo que ninguno de ellos tiene un acceso directo o privilegiado al referente:

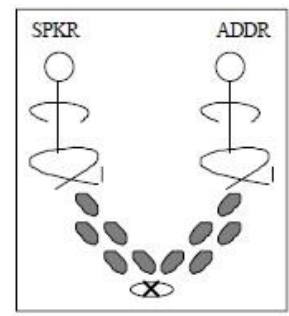

e jólva goyá si múnrni, goyá kai si ángla aménde 'la botella esa es mía, ésa que está delante de nosotros'

Debido a las características de la escena, la selección del distal nos sugiere que la distancia respecto del binomio hablante/oyente es el rasgo que determina dicha selección. Sin embargo, esta suposición debe ser revisada de acuerdo con las configuraciones de las escenas más adelante, pues en varias de ellas vuelve a aparecer este supuesto binomio. 
Por último, en este rango, está la escena (11), la que presenta una configuración bastante particular en relación con las anteriores, pues el objeto se presenta detrás del hablante, visible solo para el oyente, aunque no al alcance de su mano:

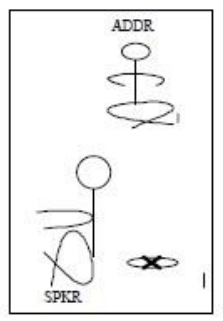

¿dikhlám e jolva goyá kai si palál pála ma?

¿viste la botella esa que está detrás de mí?

goyá jólva si bien dur tútar

'esa botella está muy lejos de ti'

A pesar de que el objeto de referencia se ubica próximo al espacio personal del hablante, los informantes presentan una preferencia por la utilización del demostrativo distal. Este uso nos sugiere que la distinción "visible/no visible" puede estar siendo codificada en el sistema demostrativo. El propio Wilkins, al referirse a los parámetros de distinción que pretenden ser codificados en las escenas de su cuestionario, señala que en relación con la escena que estamos considerando, la accesibilidad visual es el parámetro crítico que se evalúa y sugiere indagar en si la selección del demostrativo está motivada por la falta de visibilidad por parte del hablante o porque, aunque no está cercano al oyente, el objeto sí es visualmente accesible para este (Wilkins, 1999, p. 12). Para el caso del demostrativo distal de la lengua estudiada, si asumimos que a causa de la falta de acceso físico directo al objeto es la visibilidad lo que impone su uso, bien podríamos tomar ambas opciones propuestas por Wilkins, ya que ante esta "cercanía posterior" al hablante y distancia relativa al oyente (configuración que, en el contexto de espacios de menor escala, tendería hacia lo proximal), el contraste visible/no-visible para el oyente y el hablante, respectivamente, sería el criterio relevante para la selección del demostrativo.

Frente a este "caso" de referencia deíctica, nos parece factible proponer que la visibilidad es un criterio alternativo para el uso del demostrativo distal, que se manifiesta en una situación de referencia deíctica no prototípica, asumiendo que la situación canónica correspondería a un intercambio comunicativo con hablante y oyente enfrentados cara a cara.

\section{CONSIDERACIONES FINALES}

El análisis presentado hasta aquí es parcial, en el sentido de que resta por presentar el uso de los demostrativos proximal y distal en los espacios de escala media y mayor, foco de un siguiente trabajo. Sin embargo, podemos proponer dos consideraciones, a partir de lo expuesto en los apartados precedentes:

256 | AlPHA No49 (DiCIEMBRE 2019) PÁGS. 239-259. ISSN 07 16-4254 
a) Las formas identificadas como demostrativos espaciales del rromané jorajané (agrupadas en la Fig. 2) constituyen un grupo muy simétrico, que combina un componente semántico deíctico (la distinción próximo/distante) junto con contenidos gramaticales (género y número). Se trata de un sistema demostrativo binario en cuanto a la categoría de distancia respecto del centro deíctico. En cuanto a sus funciones sintácticas, los datos muestran que estos demostrativos se desempeñan tanto como adjetivos, antecediendo a un elemento nominal (es el caso de prácticamente la totalidad de los enunciados que componen nuestra muestra), como con valor pronominal. Los adverbios demostrativos, katé y koté, completan el paradigma de los demostrativos espaciales en el rromané hablado en Chile.

b) $\mathrm{Al}$ estudiar los usos exofóricos de los demostrativos del rromané, de acuerdo con el rango de situaciones espaciales sugeridas en el cuestionario de demostrativos (Wilkins, 1999), se comprueba su valor contrastivo en la localización de entidades espaciales respecto de la proximidad/no-proximidad relativa al centro deíctico. La selección del demostrativo apropiado obedece al siguiente patrón (esquematizado en la Fig. 3): el demostrativo proximal tiene su área focal en la zona próxima al hablante, mientras que el demostrativo distal incluye en su campo de aplicación tanto la zona próxima al oyente, como la zona distante al hablante.

Como hemos dicho, el uso de los demostrativos proximal y distal en los espacios de escala media y mayor, junto con una imagen general del uso de los demostrativos, será el foco de la presentación que sigue.

AGRADECIMIENTOS: esta presentación dialoga con algunos de los puntos centrales de la tesis doctoral de Lizarralde (2013), los que han sido profundizados en el contexto del Proyecto Postdoctoral 3160606 "Relaciones espaciales estáticas y dinámicas en el rromané hablado en Chile", financiado por Fondecyt. Este artículo es producto de dicho fondo investigativo.

\section{OBRAS CITADAS}

Bohnemeyer, Jürgen (2012). "Yucatec demonstratives in interaction: Spontaneous vs. elicited data", en Andrea Schalley (Ed.) Practical Theories and Empirical Practices, 99-127.

Bühler, Karl (1961[1934]). Teoría del Lenguaje. Madrid: Revista de Occidente. 
Cairns, Barbara (1991). "Spatial Deixis. The Use of Spatial Co-ordinates in Spoken Language", en Working Papers (Lund University), 38, 19-28.

Corballis, Michael (2012). "The origins of language in manual gestures", en Maggie Tellerman y Kathleen Gibson (Eds.) The Oxford Handbook of Language Evolution, 382-386.

Coventry, Kenny (2015). "Space", en Ewa Dabrowska y Dagmar Divjak (Eds.) Handbook of Cognitive Linguistics, 490-508.

Cyrulnik, Boris (2004). Del Gesto a la Palabra. La Etología de la Comunicación en los Seres Vivos. Barcelona: Gedisa.

Diessel, Holger (2006a). "Demonstratives, joint attention, and the emergence of grammar", Cognitive Linguistics, 17 (4), 463-489.

(2006b). "Demonstratives", en Keith Brown (Ed.) Encyclopedia of Language and Linguistics, Vol. 3, 430-434.

(1999). Demonstratives: form, function and grammaticalization. Amsterdam/ Philadelphia: John Benjamins Publishing Company.

Farkas, Chamarrita (2007). "Comunicación gestual en la infancia temprana: una revisión de su desarrollo, relación con el lenguaje e implicancias de su intervención", Psykhe, 16 (2), 107-115.

Fillmore, Charles (1982). "Towards a descriptive framework for spatial deíxis", en Robert Jarvella y Wolfgang Klein (Eds.) Speech, Place and Action: Studies in deixis and related topics, 31-59.

González, Álvaro y Gastón Salamanca (2011). "Aspectos de la sintaxis del rromané de Chile en textos orales tradicionales (1)", Literatura y Lingǘstica, 23, 237-260.

Hanks, William (2009). "Fieldwork on deixis", Journal of Pragmatics 41, 10-24.

— (1992). "The indexical ground of deictic reference", en Alessandro Duranti y Charles Goodwin (Eds.) Rethinking Context: language as an interactive phenomenon, 43-76.

Hellwig, Birgit (2006). "Semantics: field work methods", en Keith Brown (Ed.) Encyclopedia of Language and Linguistics, Vol. 11, 180-183.

Lenz, Friedrich (2003). "Introducción", en Friedrich Lenz (Ed.) Deictic Conceptualisation of Space, Time and Person, vii-xiv.

Levinson, Stephen (2004). "Deixis" en Laurence Horn y Gregory Ward (Eds.) Handbook of Pragmatics, 97-121.

Levinson, Stephen y David Wilkins (2006). Grammars of Space. Cambridge: Cambridge University Press.

Lizarralde, Diego (2013). Deíxis espacial y relaciones topológicas en el rromané jorajané hablado en Chile: un acercamiento desde la semántica de las expresiones espaciales. Tesis doctoral, Universidad de Concepción, Chile. 
Lizarralde, Diego y Gastón Salamanca (2017). “Cognición y semántica espacial: bases teóricas para una investigación sobre la localización estática en el rromané hablado en Chile", Papeles de Trabajo No 33, 29-52.

— (2010). "Morfología de los adjetivos demostrativos en el rromané jorajané de Chile", Literatura y Lingüística, 21, 109-126.

Lyons, John (1989[1977]). Semántica. Barcelona: Teide.

Real Academia Española (2010). Nueva Gramática de la Lengua Española. Manual. Madrid: Espasa.

Salamanca, Gastón (2006). "Notas sobre la morfología nominal del rromané, lengua de los gitanos de Chile (2)", ALPHA, 22, 209-221.

— (2005). "Vitalidad lingüística y cultural en un mundo globalizado: El caso del rromané, frente a las lenguas vernáculas chilenas", Sociedad Hoy, 8-9, 106-116.

_ (2002). Morfología nominal y verbal del romané, lengua de los gitanos de Chile. Tesis doctoral, Universidad de Concepción, Chile, 2002.

Salamanca, Gastón y Diego Lizarralde (2008). "Propuesta de un grafemario para el rromané jorajané, lengua hablada por los gitanos de Chile(1)", Universum, 23 (1), 226-247.

Samarin, William (1967). Field Linguistics, New York: Holt, Rinehard and Wiston.

Sociedad Bíblica Chilena (2007). Nuevo Testamento Romané. Brasil: Sociedades Bíblicas Unidas.

Stokoe, William (2004). El Lenguaje en las Manos. Madrid: Fondo de Cultura Económica (2013).

Tomasello, Michael. Los Orígenes de la Comunicación Humana. Buenos Aires: Katz.

Wilkins, David (1999). "1999 Demonstrative Questionnaire: "THIS" and "THAT" in comparative perspective", en David Wilkins (Ed.) Manual" for the 1999 Field Season.

Wu, Yi'an (2004). Spatial Demonstratives in English and Chinese. Amsterdam/Philadelphia: John Benjamins. 